Aus dem Seemannskrankenhause und dem Institut für Schiffs- und Tropenkrankheiten in Hamburg.

(Direktor: Med.-Rat Prof. Dr. Nocht.)

\title{
Ein Fall von Sprue und seine Behandlung.
}

\section{Von Dr. Albert Bohne, klinisebem Assistenten.}

Die zahlreichen Fäden, die Deutschland mit allen Teilen der Erde verbindet, mögen die Besprechung einer Krankheit rechtfertigen, die in Dentschland zwar selbst nicht vorkommt, aber bei dem lebhaften Verkehr mit Ostasien hierher gelangen kann. Dal3 auch für den praktischen Arzt ihre Kenntnis zuweilen von Nutzen sein kann, mag ans der Tatsache erhellen, daß 3 unser Patient durch die Hände einer ganzen Reihe von Aerzten gegangen ist, ohne dal seine Krankheit erkannt wurde. Fs handelt sich um die Sprueerkrankung, deren hauptsächlichste andere Namen sind: Tropische A phthen, Psilosis linguae, Indian Sprue. Ihre Heimat sind, soweit bekannt, die Antillen, der malayische Archipel, Indien, Ceylon, China und Japan. folgen

Es möge zunächst die Krankengeschichte unseres Patienten

S., Veterinär, 40 Jahre alt.

Anamnese: Der Vater ist an Altersschwäche, die Mutter wahrscheinlich an Magencarcinom gestorben. Drei Schwestern sind gesund. Patient hatte als Kind Masern, 1892 Syphilis. Seitdem jedes Jahr eine Schmierkur. Seit 1900 in China, wo er sich bis 1905 aufgehalten hat. Die jetzige Krankheit begann ganz allmählich im Juli 1904 mit vereinzelt auftretenden Durchfällen. Diese nahmen an Zahl zu, und Patient wurde deshalb nach Japan anf sechs Wochen beurlaubt. In China war er mit Tannalbin nnd Tannigen behandelt, in Japan mit Milchdiät und Schwefelbädern. Danach Verstopfung ziemlich hohen Grades. Allmählich wurde aber der Stuhl normal und blieb es bis 1905. Im August 1905 begann die Krankheit plötzlich wieder mit sehr heftigem Durchfall nnter starker Gasbildung. Die Stühle waren hellgelb und wäßrig. Die Zunge sowie die Mundschleimhaut waren angeblich leicht gerötet und geschwollen. Die Behandlung war eine diätetische. Die Nahrung bestand in Reissuppen. Da eine Besserung njcht eintrat, wurde er für tropendienstuntanılich erklärt ınd nach Hause geschickt. Der Durchfall hörte erst anf der Reise auf, als die kältere Gegend erreicht war. Hier ließ der Durchfall ohne Mittel nach nnd blieb während des Winters 1905/06 völlig weg. Erst im Mai 1907 trat er wieder auf, allmählich einsetzend וnd an Stärke zunehmend. Von Juni 1907 bis zu seiner Aufnahme in das Seemannskrankenhaus am 31. August war Patient in verschiedenen Bädern und Sanatorien und wurde hier mit Tannalbin, Tannigen, Fucol, Gnajacol, mit Bierscher Heißluft 11. a. behandelt, ohne daß auch nur die leiseste Besserung eintrat. Die bei der Aufnahme im Munde und an der Zunge vorhandenen Flecke sollen mindestens seit 1905 bestehen. Eine Ursache für seine Krankheit kann Patient nicht angeben.

31. Angust 1907. Befnnd: Mäßig kräftiger, ziemlich stark abgemagerter Patient mit blasser Gesichtsfarbe. Haut: trocken, welk, ohne Ausschläge. Die Brustorgane sind ohne Besonderheiten. Leib: leicht anfgetrieben, weich, nirgends druckempfindlich, mäßig starkes Gurren. Leber: oberer Rand der sechsten Rippe, einen Querfinger oberlialb des Rippenbogens. Mils: nicht palpabel, anch perkutorisch nicht vergrößert. Zunge: stark geschwollen, die Oberfläche ist glatt, atrophisch und zeigt ein zerklüftetes Aussehen. Am Rande deutliche Zahneindrücke. Irgend welche Flecke sind weder an der Zunge noch an der Mundschleimhaut wahrzunehmen. Appetit: sehr schlecht. Rachenorgane: ohne Besonderheiten. Drüsen: nicht vergrößert. Reflexe: ohne Besonderheiten. Körper. gewicht: $55 \mathrm{~kg}$. Urin ist frei von Eiweiß und Zncker. Das Blut hat einen Hämoglobingehalt von 75 and zeigt mikroskopisch keine Veränderungen. Stuhl: es bestehen starke Durchfälle unter außerordentlicher Gasentwicklung, 10 bis 15 pro Tag. Die Stiihle sind hellgelb, homogen. Bakteriologisch weder Typhns-, Paratyphusnoch Dysenteriebazillen nachweisbar. Körpertemperatur ist stets 
wormal. Der Puls ist ziemlich klein, regelmäbig. zuischen 90 und 100

Therapie: Absolute Milchdiät.

5. September. Die Zunge ist abgeschwollen. Am zweiten rochten unteren Schneidezahn ein etwa linsengroßes, rundes, leicht crhabenes, blabrötliches Bläschen. Die Durchfälle haben bcreits bodeutend nachgelassen (zwei Stühle pro Tag), Gasbildung nicht mehr vorhanden.

13. September. Milchdiät wird gut vertragen, Patient trinkt bis zu 14 Flaschen pro Tag, das sind sieben Liter. Alle Taye ein Stuhl von breiiger Konsistenz. Das Blaschen am Zahnfleisch des Schneidezahns ist im Abheilen begriffen.

22. September. Die Schwellung der Zunge ist verschwunden. Die Oberflache zeigt nicht mehr die Glätte wie bei der Aufnahme.

25. September. Patient fühlt sich subjektiv sehr wohl und ist ohne Beschwerden. Der Stuhlgang ist regelmäBig geblieben. Patient verträgt bereits eine ganze Anzabl fester, leichter Speisen, \%. B. Kalbsbraten, Fische, Hack, Kükenragout, Blumenkohl n. a. Die Zunge zeigt nur noch geringe Glätte und wenig Furchen. Sie ist nicht mehr geschwollen, das Bläschen ist abgeheilt. Patient wird mit genauer Diätvorschrift entlassen. Er hat während seines Allfenthaltes im Krankenhause $8,2 \mathrm{~kg}$ an Gewicht zigenommen, Der Hämoglobingrehalt ist anf $86^{\circ}$ gestiegen.

Unser Patient zeigt also alle fiu Sprue charakteristischen Zeichen: Die glatte, zerklüftete und besonders an den vorderen Partien atrophische \%unge, an der Mundschleimhaut die kleinen erhabenen, scharf lumschriebenen Bläschen, die profusen Durchfälle unter starker Gasbildung, den negativen Ausfall der bakteriologrischen Stuhlıntersuchung, ein Symptomkomplex, der die Krankheit leicht von äbnlichen trennen läbt. Damit ist auch gesagt, was wir bis jetzt über die A etiologie der Sprueerkrankung wissen, nämlich niehts. Natürlich sind auch hier Bakterien und Protozoen als Erreger angesprochen. Bis jetzt hat abcr weder von den einen noch von den anderen ein Vertieter sich allgemeine Anerkenmung verschaffen können. Ueber das Wesen der Krankheit wissen wir, daß sie nur in heißen Ländern vorkommt, nje epidemisch anftritt und nicht kontagiös ist. Frauen sollen öfters befallen werden als Männer. Pathologisch-anatomisch finden sich die hauptsächlichen Veränderungen auber an der Zunge am Dänndarm, der ebenfalls wie die Zunge hochgradig atrophische Teränderungen zeigt. Was nun die Therapie betrifft, so hat sich in unserem Ealle die absolute Milchdiait auf das beste bewährt. Dank der Geduld des Patienten konnton wir drei Wochen nichts als Milch geben und hatten doch noch die Genugtmung, eine Gewichtszunahme konstatieren zu können. Allnählich gingen wir zu konsistenterer Nahrung über, bis wir den Patienten mit einem zienlich reichhaltigen Speisezettel entlassen konnten. Trotz des giinstigen Erfolges hielten wir Patienten noch nicht für geheilt, eine Vorsicht, die durch den weiteren Verlaulf gerechtfertigt wurde. Patient bekam namlich in der Folgezeit nach seiner Entlassung noch mehrere Rückfälle, die aber unter Milch diät bald wieder behoben wurden. Ueber den endguiltigen Ausgang des Falles läßt sich auch jetzt mit Sicherheit nichts sagen. 